\title{
A INTERFERÊNCIA NA AUTONOMIA REPRODUTIVA FEMININA SOB A ÓTICA DA DESIGUALDADE DE GÊNERO
}

\section{INTERFERENCE IN WOMENS'S REPRODUCTIVE AUTONOMY UNDER THE VIEW OF GENDER INEQUALITY}

Núbia dos Santos Cruz*

\begin{abstract}
RESUMO: Artigo proposto, a analisar as questões bioéticas na contemporaneidade, no que se refere às interferências na autonomia reprodutiva feminina sob a ótica da desigualdade de gênero, para isso se faz necessária uma abordagem teórica interdisciplinar da bioética, em especial a Bioética Feminista e o Direito. Desde a década de 90, os direitos humanos sexuais e reprodutivos vêm sendo incorporados por intermédio da adesão aos acordos internacionais pelo governo brasileiro, assumindo obrigações internacionais de tomar medidas para a sua implementação através de leis e políticas públicas no âmbito nacional, enfatizando que os direitos das mulheres são direitos humanos. A sociedade civil trabalha para a igualdade de direitos entre homens e mulheres e para a efetiva implementação dos direitos das mulheres, no sentido de garantir que o Estado dê a devida atenção aos temas que afetam direta e especificamente a saúde das mulheres, e os direitos sexuais e reprodutivos. 0 caminho metodológico abordado é de cunho qualitativo. Trabalha em sua primeira parte com uma breve reflexão sobre gênero, bioética e a conceituação sobre autonomia, na segunda parte evidência a relação da bioética feminista e a autonomia reprodutiva, em sua terceira parte, levanta a questão da desigualdade de gênero no Brasil, por fim, traz as considerações finais desta pesquisa pontuando como a bioética feminista pensa e estuda os conceitos de gênero e feminismo para compreender e apreender a diferença moral entre as partes em conflito e vulnerabilidade, e sua importância no meio acadêmico, social e jurídico.
\end{abstract}

PALAVRAS-CHAVE: Autonomia reprodutiva. Bioética feminista e gênero. Desigualdade de gênero.

ABSTRACT: Proposed article, analyzing bioethical issues in contemporary times, with regard to interferences in female reproductive autonomy from the perspective of gender inequality, for this it is necessary an interdisciplinary theoretical approach to bioethics, especially Feminist Bioethics and the Right. Since the 1990s, sexual and reproductive human rights have been incorporated through adherence to international agreements by the Brazilian government, assuming international obligations to take

\footnotetext{
* Mestranda em Direito pela Universidade Federal da Bahia. Pós-Graduanda em Ciências Criminais pela Estácio de Sá. Bacharela em Direito pela Universidade Católica do Salvador. Especialização em Psicopedagogia Institucional pela Universidade Anhanguera - UNIDERP. Licenciada em Letras com Habilitação em português, inglês e nas respectivas Literaturas pela Faculdade Cenecista de Senhor do Bonfim. Pós-graduanda em Cultura e Literatura pela Universidade Candido Mendes. Mediadora Extrajudicial, Conciliadora e Negociadora de Conflitos Consensuais. E-mail: nubiacruzadv@gmail.com.
} 
measures for their implementation through laws and public policies at the national level, emphasizing that human rights women's rights are human rights civil society works for equal rights between men and women and for the effective implementation of women's rights, in order to ensure that the State gives due attention to issues that directly and specifically affect women's health, and sexual and reproductive rights. The methodological approach is of a qualitative nature. It works in its first part with a brief reflection on gender bioethics and the concept of autonomy, in the second part it highlights the relationship of feminist bioethics and reproductive autonomy, in its third part, it raises the question of gender inequality in Brazil, finally, brings the final considerations of this research, pointing out how feminist bioethics thinks and studies the concepts of gender and feminism to understand and apprehend the moral difference between the conflicting and vulnerable parts, and their importance in the academic, social and legal environment.

KEYWORDS: Reproductive autonomy. Feminist bioethics and gender. Gender inequality.

\section{INTRODUÇÃO}

Um dos pilares da Bioética é o princípio da autonomia. O vocábulo autonomia deriva do grego: Autos - próprio; Nomos - norma, lei. O termo autonomia possui raízes na filosofia kantiana, e tem por significado a capacidade de se autogovernar, a autodeterminação, o que pressupõe conhecimento, verdade e informação.

Para que um indivíduo seja considerado autônomo, capaz de realizar escolhas autônomas, é imprescindível que este indivíduo aja intencionalmente e que tenha liberdade nesse agir. Essa liberdade deve ser livre de qualquer interferência de cunho interno ou externo, em que tenha respeitada a sua intimidade, seus valores e crenças.

Nesta perspectiva, deve-se pensar na autonomia sob a ótica da desigualdade de gênero, pois, existe um paradoxo social de uma igualdade já presente no seio da sociedade, no entanto as mulheres convivem diariamente com diversas tensões, a exemplo das várias violências domésticas (morais, psicologias, sexuais, físicas...), as próprias desigualdades sociais- classe, raça e gênero e mesmo as privações aos espaços públicos. Diante desse contexto, surge à problemática: Existe realmente interferência na autonomia reprodutiva feminina? A mulher apesar das desigualdades ainda consegue se impor sobre seu corpo e sua autonomia reprodutiva?, perante 
essas questões, tem-se por hipótese, que as sociedades são reprodutoras de desigualdades de gênero, portanto interferem na autonomia reprodutiva feminina.

As mulheres vêm a décadas buscando direitos, entre eles o acesso aos serviços e ações de saúde de qualidade, e a implantação de políticas públicas que incluem a saúde sexual e reprodutiva. Com os movimentos feministas no qual as mulheres reivindicavam direitos iguais, inclusive o direito de decidir sobre o seu próprio corpo, o processo de emancipação da mulher e o avanço na laicização dos Estados, desencadearam várias discussões ${ }^{1}$.

Trata-se, de uma pesquisa qualitativa, de natureza exploratória. Ademais, é relevante para a compreensão e o entendimento da contribuição das mulheres, pois possibilita avanços nos debates que tentam superar nas desigualdades de gênero. Nesta perspectiva este artigo tem por objetivo, analisar as questões bioéticas na contemporaneidade no que se refere à autonomia reprodutiva feminina sob a ótica da desigualdade de gênero.

Para um entendimento alinhado, este trabalho remeterá uma breve reflexão conceitual de autonomia, da bioética feminista, as questões de gênero, em relação à autonomia reprodutiva sob a ótica da desigualdade de gênero, e pontua como a bioética feminista pensa e estuda os conceitos de gênero e feminismo para compreender e apreender a diferença moral entre as partes em conflito e vulnerabilidade, e sua importância no meio acadêmico, social e jurídico.

\section{CONCEITUANDO A AUTONOMIA: REFLEXÕES BIOÉTICAS}

No Brasil, a bioética está vinculada à prática médica e a temas de saúde, mas o início das pesquisas se deu de maneira mais incisiva por acadêmicos de outras áreas, estudiosos das ciências sociais e humanas, além de operadores do direito ${ }^{2}$. A

\footnotetext{
1 ANJOS, K. F.; SANTOS, V. C.; SOUZAS, R.; EUGÊNIO, B. G. • Aborto e saúde pública no Brasil: reflexões sob a perspectiva dos direitos humanos. Saúde em Debate - Rio de Janeiro, v. 37, n. 98, p. 504-515, jul/set 2013. Disponível em https://www.scielosp.org/pdf/sdeb/2013.v37n98/504-515/pt. Acesso em 10 out. 2019.

2 BANDEIRA, Lourdes. ALMEIDA, Tânia Mara Campos de. Bioética e feminismo: um diálogo em construção. Revista de Bioética. 2008, p. 180.
} 
Bioética vem integrando a cultura técnica - cientifica das ciências naturais, cultura humanística, examinada a luz dos princípios e valores e princípios morais ${ }^{3}$.

Conforme Beauchamps e Childress existem, quatro níveis no raciocínio moral: os princípios gerais, as teorias éticas, as normas e os juízos e ações morais particulares. Em que, a justificação dos juízos particulares é baseada nas normas, as normas nos princípios, e a dos princípios nas teorias éticas.

Beauchamps e Childress propõem quatro princípios: a autonomia, beneficência, não-maleficência e a justiça ${ }^{4}$. A autonomia pode ser aplicada em vários contextos, na Bioética, segundo Aguiar e Meirelles, a autonomia ocupa um lugar de destaque na configuração geral das relações sociais ${ }^{5}$, desde 0 direito de consentir sobre determinado tratamento terapêutico à recusa de propostas de caráter preventivo ou diagnóstico.

$\mathrm{Na}$ Bioética, o princípio da autonomia é conhecido como o princípio do respeito às pessoas. Exige-se que a sociedade aceite que os indivíduos se autogovernem, sejam autônomos, nas suas escolhas. O princípio da beneficência requer que sejam atendidos os interesses importantes e legítimos dos indivíduos e, na medida do possível, sejam evitados danos. Já o princípio da não-maleficência, está fundamentado em não causar danos. O princípio da justiça exige equidade na distribuição de bens e benefícios, uma pessoa é vítima de uma injustiça, quando Ihe é negado um bem ao qual tem direito e que lhe é devido.

No entanto, a abordagem que se faz neste artigo é da bioética feminista que diverge e resiste ao principialismo. Formalmente, a Bioética de base feminista emergiu das críticas intensas às desigualdades sociais, em particular, as de gênero, abalando os pressupostos universalistas e abstratos do principialismo. Vale pontuar, que a Bioética principialista teve e tem sua importância no campo Bioético, sobretudo para aqueles que são adeptos dessa corrente, tanto para os critérios de resoluções de

${ }^{3}$ MARCOLINO, Jan; COHEN, C. Sobre a correlação entre a bioética e a psicologia médica. Rev. Assoc. Med. Bras. 2008. p.365.

${ }^{4}$ BEAUCHAMP,TL, CHILDRESS JF. Principles of biomedical ethics 3rd ed. New York (NY): Oxford University Press; 1989, p.28.

${ }^{5}$ AGUIAR, Mônica Neves. MEIRELLES, Ana Thereza. Autonomia e Alteridade como fundamentos da construção do sentido de dignidade existencial diante do direito à vida. Revista Brasileira de Direito Animal. RBDA, SALVADOR, V.13, N. 01, Jan-Abr 2018, pp. 123-147. 
conflitos morais, devendo ser observados como prima facie nas ponderações em situações problemas, quanto de igualdade de condições.

A autonomia não deve ser vista nem convertida em Direito absoluto, existe limites, e seus limites são observados pelo respeito à dignidade e à liberdade aos outros e da coletividade ${ }^{6}$. Pessoas autônomas autodeterminam-se, agem livremente, em conformidade com suas escolhas, ações, deliberações, essa liberdade de decidir ou não, de mudança de opinião é que torna essa pessoa autônoma, pois não existe interferência interna ou externa nesse agir. Uma ação pode ser considerada autônoma, 1- quando possui intenção, e essa intenção não admite nenhum nível de grau, 2- que o agente da ação tenha compressão do que está fazendo/ realizando, e 3- que não sofra influência externa, que tenha total liberdade nessa ação ${ }^{7}$.

Autonomia não se confunde com individualismo, em verdade existe uma dualidade no centro do pensamento de individualismo, em que as normas sociais além de viabilizar a livre realização do indivíduo, conferem-lhe o arbítrio para julgar e exercer a sua autonomia, dentro de certos limites, pois o ser humano vive em sociedade, e a própria ética é um dos mecanismos de regulação das relações ${ }^{8}$.

Autonomia tem por significado o direito de consentir ou recusar propostas de caráter preventivo, diagnóstico ou terapêutico que afetem ou venham a afetar sua integridade físico-psíquica ou social. Livre de restrições internas, causadas por distúrbios psicológicos, e livres de coerções externas, por pressão de familiares, amigos e principalmente dos profissionais de saúde. A pessoa autônoma também tem o direito de não ser informada, quando assim for sua vontade expressa, pois ser informado, também é um direito e não uma obrigação para a pessoa?

Questões relacionadas à autonomia feminina, seja à reprodução, à sexualidade, ao corpo, são algumas das áreas para as quais os resultados das

\footnotetext{
${ }^{6}$ FERRER, Jorge José; ALVAREZ, Juan Carlos. Para fundamentar a bioética. Teorias e paradigmas teóricos na bioética contemporânea. São Paulo: Loyola. 2005.p.123.

${ }^{7}$ FERRER, Jorge José; ALVAREZ, Juan Carlos. Para fundamentar a bioética. Teorias e paradigmas teóricos na bioética contemporânea. São Paulo: Loyola. 2005.p.124.

8 VARES, Sidnei Ferreira de. SOCIOLOGISMO E INDIVIDUALISMO EM ÉMILE DURKHEIM. CADERNO CRH, RESENHA TEMÁTICA. Salvador, v. 24, n. 62, Maio./Ago. 2011. p. 435-446. Disponível em http://dx.doi.org/10.1590/S0103-49792011000200013. Acesso em 26 de nov. 2019. ${ }^{9}$ FERRER, Jorge José; ALVAREZ, Juan Carlos. Para fundamentar a bioética. Teorias e paradigmas teóricos na bioética contemporânea. São Paulo: Loyola. 2005.p.125.
} 
pesquisas de gênero contribuíram e vem contribuindo diretamente, indagações importantes como, de quem é o corpo? Seria ele, da pessoa interessada, do seu círculo familiar, de um Deus que Ihe doou, de uma natureza que o quer inviolável, de um poder social que de mil maneiras dele se apossa, de um médico, de um magistrado que estabelece seu destino? $\mathrm{E}$ de qual corpo estamos falando ${ }^{10}$, traz reflexões pertinentes sobre os modos de uso do corpo, sua liberdade e os modos de sua coerção.

Pois bem, o que se percebe, frente às referências históricas, sociais e familiares é como as relações e o controle da sociedade vai tomando o corpo feminino para si, e o quanto a autonomia sobre o próprio corpo, ainda estar vinculada ao não contrariar os bons costumes ${ }^{11}$. E é nesses termos, que se faz imprescindível um estudo pautado em gênero, visto que um recorte em gênero amplia a percepção sociológica, uma vez que os pressupostos em gênero são um desafio adicional ao raciocínio ético, portanto, cabe essa vinculação de autonomia, Bioética e gênero, e lembrando que a linha teórica de estudo é a Bioética feminista.

\section{1- BIOÉTICA E GÊNERO}

Os estudos de gênero e bioética começam a se aproximar, quando a bioética adentra no campo de estudos relacionados à reprodução biológica, bem como a pesquisa com seres humanos. Essa aproximação da bioética com os estudos de gênero percorre duas vertentes, a primeira pelo reconhecimento de gênero como variável nas pesquisas, levando em consideração para as análises, e a segunda vertente se dá pelo diálogo com as próprias teorias gênero sobre vulnerabilidade, desigualdade, corpo, sexualidade e reprodução, o que fez com que se cunhasse a Bioética Feminista ${ }^{12}$.

${ }^{10}$ BARBOZA, Heloisa Helena Gomes; JUNIOR, Vitor de Azevedo Almeida. (Des)lgualdade de gênero: restrições à autonomia da mulher. Revista de ciências Jurídicas. Pensar, Fortaleza, v. 22, n. 1, jan./abr. 2017 p. 240-271.

${ }^{11}$ BARBOZA, Heloisa Helena Gomes; JUNIOR, Vitor de Azevedo Almeida. (Des)lgualdade de gênero: restrições à autonomia da mulher. Revista de ciências Jurídicas. Pensar, Fortaleza, v. 22, n. 1, jan./abr. 2017 p. 240-271.

12 BANDEIRA, Lourdes. ALMEIDA, Tânia Mara Campos de. Bioética e feminismo: um diálogo em construção. Revista de Bioética. 2008, p. 179. 
Os estudos de gênero buscavam e buscam compreender como os papéis do masculino e do feminino são definidos e incorporados por diferentes grupos sociais, a partir desse reconhecimento e com essa compreensão de masculinidade e feminilidade a sociedade e seus indivíduos vão se percebendo enquanto sujeitos, os resultados advindos foram dados por meio dos estudos de gênero, que mostraram que essas definições de masculino e feminino são dispostas pelas socializações e não pelas significações biológicas ${ }^{13}$.

A expressão nasce-se macho e fêmea, e aprende-se a ser homem e mulher, é a que durante um longo tempo, ganhou impulso quando a feminista francesa Simone de Beauvoir, lança o livro o segundo sexo, descontruindo a hierarquização entre os sexos, demonstrando que a condição social das mulheres não era uma simples questão biológica, mas fruto de uma construção social desenvolvida na sociedade patriarcal $^{14}$.

O reconhecimento dos papéis e as definições do masculino e do feminino, resultando na categoria gênero ampliou o campo de visão de muitos estudos e estudiosos, oportunizando a sensibilidade e humanização ao processo, uma vez que homens e mulheres são singulares em suas dores e enfermidades. No campo dos conflitos morais em saúde, objeto de pesquisa e análise da bioética, os pressupostos de gênero tornam-se um desafio adicional ao raciocínio ético. Alguns temas-chaves da bioética no Brasil estão relacionados à reprodução biológica e social e, portanto, diretamente vinculados às questões de gênero ${ }^{15}$.

E na reivindicação pela igualdade de direitos dos excluídos, de equidade no tratamento de homens e de mulheres e na discussão profunda de eternos problemas, preconceitos, estereótipos, misoginias e tabus da humanidade, o papel da

\footnotetext{
${ }^{13}$ DINIZ, Débora. Bioética e gênero. Revista Bioética. Capa> v. 16, n.2> Diniz. 2008, p. 208. Disponível em http://revistabioetica.cfm.org.br/index.php/revista_bioetica/article/view/68/71. Acesso em 30 nov. 2019.

${ }^{14}$ BEAUVOIR, Simone de. 0 segundo sexo: fatos e mitos. Trad. Sérgio Milliet. 3 ed. Rio de Janeiro: Nova Fronteira, 2016, p. 47.

${ }^{15}$ BANDEIRA, Lourdes. ALMEIDA, Tânia Mara Campos de. Bioética e feminismo: um diálogo em construção. Revista de Bioética. 2008, p.185.
} 
Declaração Universal sobre Bioética e Direitos Humanos ${ }^{16}$, promulgada pela UNESCO em 2005, constitui um marco central dessa nova dimensão, pois reafirma a importância do respeito aos direitos humanos enquanto condição essencial à saúde e cidadania dos povos.

Todos os desdobramentos que a discussão na área traz, desde a clonagem, passando pela eutanásia até o Projeto Genoma Humana, podem atingir quaisquer seres humanos, algumas problemáticas mais diretamente as mulheres (como o aborto e/ou uso de tecnologias reprodutivas), tudo isso têm um peso social extremamente significativo para o pensamento feminista.

\section{A AUTONOMIA REPRODUTIVA: LIBERDADE GESTACIONAL E MATERNA.}

Foi a partir dos anos 60, com os movimentos em defesa dos direitos fundamentais da cidadania que ocorreu a conquista pela autonomia, especialmente com as reinvindicações em direito à saúde e humanização.

A definição de autonomia reprodutiva está assentada no princípio ético, um dos eixos fundamentais das teorias bioéticas. Assim, a autonomia reprodutiva seria um valor que abrange a interrupção seletiva ou voluntária da gestação, bem como todas as questões pertinentes à saúde reprodutiva ${ }^{17}$. Dada esta autonomia, foram sendo ampliadas as técnicas de diagnóstico pré-natal e o avanço da genética e o leque das possibilidades de escolhas reprodutivas, permitindo, por exemplo, a seleção em casos de diagnóstico de má-formação fetal ${ }^{18}$.

A Constituição Federal de $1988^{19}$ dispõe que são direitos fundamentais da pessoa humana, o direito à vida, à igualdade, à liberdade e à segurança, assim como, os direitos sexuais e reprodutivos que também integram o rol de direitos e merecem proteção constitucional. Todos os direitos fundamentais são importantes e devem ser

${ }^{16}$ COMISSÂO NACIONAL DA UNESCO - Portugal - Declaração Universal sobre Bioética e Direitos Humanos. Organização das Nações Unidas para a Educação, Ciência e Cultura. Disponível em: https://unesdoc.unesco.org/ark:/48223/pf0000146180 por. Acesso em 04 de maio 2020.

17 DINIZ, Debora. ALMEIDA. Marcos de. Bioética e Aborto. In. Iniciação a Bioética. Brasília: Conselho Federal de Medicina. 1998. p. 125-137.

${ }^{18}$ DINIZ, Debora. Autonomia reprodutiva: um estudo de caso sobre a surdez. Rio de Janeiro: Cad. Saúde Pública. 2003, p.179.

${ }^{19}$ BRASIL. CONSTITUIÇÃO DA REPÚBLICA FEDERATIVA DE 1988. Brasília, 5 de outubro de 1988. 
respeitados, sem exceção, pois só assim será possível, a construção de uma sociedade livre, justa e solidária, com respeito à cidadania e à dignidade da pessoa humana.

O Ministério da Saúde resolveu listar ${ }^{20}$ os direitos sexuais e reprodutivos da pessoa humana, visando o respeito a esses direitos, inclusive, por entender que é uma questão de saúde pública. A título de exemplificação, tem-se, o Direito de viver e expressar livremente a sexualidade sem violência, discriminações e imposições e com respeito pleno pelo corpo do (a) parceiro (a). Direito de escolher o (a) parceiro (a) sexual. Direito de viver a sexualidade independentemente de estado civil, idade ou condição física. Direito de ter relação sexual independente da reprodução. Direito de expressar livremente sua orientação sexual: heterossexualidade, homossexualidade, bissexualidade, entre outras. Direito à informação e à educação sexual e reprodutiva. Direito ao sexo seguro para prevenção da gravidez indesejada e de DST/HIV/AIDS. Direito das pessoas de decidirem, de forma livre e responsável, se querem ou não ter filhos, quantos filhos desejam ter e em que momento de suas vidas. Direito a informações, meios, métodos e técnicas para ter ou não ter filhos.

Muitas pessoas, casadas ou não, entendem que autonomia reprodutiva, liberdade gestacional, é ter a oportunidade, condições financeiras e educacionais de realizarem um planejamento reprodutivo. Esse é mais um direito sexual e reprodutivo, previsto na Constituição Federal e regulamentado pela Lei no 9.263, de 12 de janeiro de 1996, pela qual, a mulher, o homem ou o casal tem o direito de decidir o número de filhos que pretendem ter. Ninguém pode obrigar uma mulher a utilizar um método contraceptivo ou a limitar o número de filhos, assim como ninguém pode privá-la de usar algum método anticoncepcional e de escolher sobre a quantidade de filhos que ela deseja ter ${ }^{21}$.

O Sistema Único de Saúde (SUS) fornece alguns serviços em sua rede de atendimento, para atender e garantir o mínimo de um planejamento considerado adequado. Em toda sua rede de serviços existem a orientação, a assistência e um

20 Ministério da Saúde, Secretaria de Atenção à Saúde, Departamento de Ações Programáticas Estratégicas. Direitos sexuais, direitos reprodutivos e métodos anticoncepcionais. Brasília: Ministério da Saúde, 2006.

${ }^{21}$ BRASIL. LEI № 9.263, Lei Planejamento Familiar. Brasília. 12 DE JANEIRO DE 1996. 
atendimento a essas mulheres e casais. Tanto a mulher que deseja ter filhos como aquela que não deseja ter filhos deve receber orientação adequada; um atendimento pré-natal, assistência ao parto, ao puerpério e ao neonato. Realização de aborto legal nos casos de estupro, quando da gravidez decorrer risco de vida para a gestante, e interrupção de gestação de feto anencéfalo (conforme Resolução no1989/2012 do CFM) ${ }^{22}$.

Só que, durante um longo período, e aqui se pode pontuar que até a nossa contemporaneidade, a maternidade foi intrinsecamente pensada como função feminina por excelência, concernente à natureza da mulher, isso porque nossa sociedade tem por cultura a mãe como única ou principal responsável pela criação, desenvolvimento, e cuidado para com as crianças, embora autores como $\mathrm{Nancy}^{23} \mathrm{e}$ Badinter $^{24}$ apontem para o fato de que essa dedicação da mulher ao papel materno deva-se muito "a uma transposição social e cultural das suas capacidades de dar à luz e amamentar". A maternidade sempre foi considerada como o eixo central da situação da mulher na sociedade e na família.

A recusa consciente da maternidade significava muito mais do que negá-la como fatalidade biológica, mas a possibilidade de conquista da autonomia feminina, no entanto, essa maternidade foi frequentemente oferecida, como explicação para a exclusão das mulheres na política, no mercado de trabalho, do espaço público, como a raça é dada como razão da escravização e/ou sujeição dos negros, quando de fato a relação de causalidade se dá ao inverso: são processos de diferenciação social, que produzem exclusões e escravizações que são justificadas em termos de biologia ou/e de raça. O elevado senso de identificação que surge com a redução de um indivíduo a uma categoria é, ao mesmo tempo, devastador, embriagador, e totalmente inaceitável ${ }^{25}$.

22 MINISTÉRIO DA SAÚDE. Secretaria de Atenção à Saúde, Departamento de Ações Programáticas Estratégicas. Direitos sexuais, direitos reprodutivos e métodos anticoncepcionais. Brasília: Ministério da Saúde, 2006.

${ }^{23}$ CHODOROW, Nancy. Psicanálise da Maternidade: Uma Crítica a Freud a Partir da Mulher. Rio de Janeiro: Rosa dos Tempos, 1991.

${ }^{24}$ BADINTER, Elisabeth. B126a. Um Amor conquistado: o mito do amor materno. Elisabeth Badinter; tradução de Waltensir Dutra. - Rio de Janeiro: Nova Fronteira, 1985, p. 85.

${ }_{25}$ SCOOTT, Joan W. $O$ enigma da igualdade. Rev. Estud. Fem. v.13 n.1 Florianópolis jan./abr. 2005. 
Portanto, determinados discursos hegemônicos sobre maternidade, é excludente, uma vez que é utilizada como prática supressora e sexista frente às mulheres, para isso a necessidade de um estudo em uma teoria feminista, como pontua Almeida e Bandeira ${ }^{26}$, a ética feminista caminha na mesma direção de descontruir a estrutura axiológica hegemônica, presente na maioria das instituições e nas práticas médicas habituais sobre o corpo feminino.

\subsection{BIOÉTICA FEMINISTAS}

Há de se reconhecer, a relevância da utilização de uma abordagem de gênero, na análise dos processos sociais e para a ocorrência da inclusão de novos conceitos, até então esquecidos quando envolvia a relação de homens e mulheres. A bioética feminista estuda os oprimidos, os vulneráveis, e tem como proposta a revolução, os estudos revolucionários, centrada não apenas na diferença biológica entre sexos, mas na diferenciação social dos gêneros.

Valer pontuar, que nem toda ética feminista se pauta na ética do cuidado, ela pode se pautar na ética do poder E aqui, cabe uma distinção, uma vez que a ética do cuidado está muito associada a valores tradicionais, imputadas ao ser feminino, da simpatia, da nutrição, sensibilidade e cuidado, enquanto a ética do poder se impõe a modificação do sistema e da estrutura, que contribui para a opressão das mulheres na sociedade ${ }^{27}$.

O conceito de "ética do cuidado" foi desenvolvido, como parte de uma teoria sobre as "diferentes vozes femininas", para que identificasse duas perspectivas na resolução de problemas morais. A primeira diz respeito, a "ética da justiça", baseada em relações hierarquizadas entre os sujeitos de direito. A segunda é a ética do cuidado, baseada na habilidade de cuidar e de proteger os outros, utilizada geralmente pelas mulheres estadunidenses, que leva em consideração os detalhes e

${ }^{26}$ BANDEIRA, Lourdes. ALMEIDA, Tânia Mara Campos de. Bioética e feminismo: um diálogo em construção. Revista de Bioética. 2008, p. 176.

${ }^{27}$ FERRER, Jorge José; ALVAREZ, Juan Carlos. Para fundamentar a bioética. Teorias e paradigmas teóricos na bioética contemporânea. São Paulo: Loyola. 2005. 
complexidades de relacionamentos emocionais entre os indivíduos para a solução dos conflitos $^{28}$.

As ações intrínsecas ao cuidado, como o respeito, atenção, efetiva preocupação com o outro e o cuidado no desenrolar das relações, estão na base da ética do cuidado. O cuidado nos impõe o dever de olhar com atenção para aquele que está ao lado, sejam filhos, familiares, pacientes, vizinhos, amigos e, a partir de ações positivas, desenvolver nossa capacidade afetiva e o despertar natural da compaixão. Nesta concepção, o cuidado passa a ser visto como uma atitude responsável visando incrementar o bem-estar ou o modo de vida do indivíduo ou do grupo, a partir de seus desejos, necessidades e vulnerabilidades ${ }^{29}$.

Algumas feministas liberais têm criticado a teoria do cuidado, afirmando que ela é essencialista, por afirmar que as características do cuidado e da solidariedade são inerentes às mulheres, embora muitas mulheres não sejam naturalmente cuidadosas e muitos homens o sejam. Atribuir essas características feminiza as mulheres de uma forma prejudicial, pois tanto homens como mulheres possuem uma idêntica articulação e sensibilidade moral ${ }^{30}$.

Seja como for, a ética do cuidado repele o modelo de deliberação moral que determina uma tomada de decisão baseada em princípios e regras universais, reivindicando que as decisões sejam concretizadas a partir da análise do caso concreto, da observação do contexto e de suas relações afetivas. Por isso, a abordagem feminista nos estudos acadêmicos, seja na área de sociologia, ou de saúde, deve ser associada a uma concepção de conhecimento e (re) apropriação do

28 FAUTH, Juliana de Andrade. Entendendo o direito animal e o especismo: uma breve leitura ecofeminista. Revista Jus Navigandi, ISSN 1518-4862, Teresina, ano 19, n. 3915, 21 mar. 2014. Disponível em: https://jus.com.br/artigos/27043. Acesso em: 19 nov. 2019.

29 CONPEDI/ UNISINOS. Biodireito e direitos dos animais [Recurso eletrônico on-line]. ECOFEMINISMO E DIREITO ANIMAL. Organização Coordenadores: Valéria Silva Galdino Cardin; Heron José de Santana Gordilho. - Florianópolis: CONPEDI, p.126. 2018. ISBN: 978-85-5505-685-7. Disponível em: http://conpedi.danilolr.info/publicacoes/34q12098/ryzk920n/T6peyBzVU76ft2Tx.pdf. Acesso em 14 nov. 2019.

${ }^{30}$ GORDILHO, Heron José de Santana. SOUZA, Marinês Ribeiro De. Ecofeminismo e Direito animal. Biodireito e direitos dos animais. Organização CONPEDI/ UNISINOS. Florianópolis: CONPEDI, 2018, p. 125. 
próprio corpo. Corpo esse que não deve ser território da dominação masculina e objeto de "propriedade" ${ }^{31}$.

Quando o movimento de mulheres começa com a afirmação "Nosso corpo nos pertence", trava um reconhecimento de existência, de identidade, de autonomia, com isso, as lutas giram entorno pelo direito de decidir sobre esse corpo, seja em questões de procriação, de sexualidade, na interrupção da gravidez. Só então, constituídas enquanto sujeito feminino, capaz de falar na primeira pessoa, de dizer a partir de sua própria percepção, as reivindicações de autonomia nas esferas sexual e reprodutiva surgem/eclode ${ }^{32}$.

Essas mulheres tornam-se agora, sujeitos políticos, pois trazem consigo as questões do espaço privado para o espaço público. O espaço privado era o espaço de relações de poder, dominação e hierarquia, nas quais as mulheres constituíam o pólo dominado, ainda uma realidade contemporânea em muitos espaços privados, segundo dados do Anuário Brasileiro de Segurança Pública ${ }^{33}$ e o Atlas da Violência de $2019^{34}$.

O acesso ao espaço público e a utilização política do conceito de saúde reprodutiva feminista, proporcionou às mulheres, condições de apropriação de seu potencial reprodutor e de sua reprodução efetiva, fazendo agora da maternidade uma escolha, não mais uma fatalidade biológica, ou um determinismo social. Isso ocorre, desde a reabertura democrática no Brasil, em meados da década de 1980, quando as organizações da sociedade civil começam a trabalhar para a igualdade de direitos

${ }^{31}$ GORDILHO, Heron José de Santana. SOUZA, Marinês Ribeiro De. Ecofeminismo e Direito animal. Biodireito e direitos dos animais. Organização CONPEDI/ UNISINOS. Florianópolis: CONPEDI, 2018. ${ }^{32}$ ITABORAÍ, Nathalie Reis.Mudanças nas famílias brasileiras (1976-2012): uma perspectiva de classe e gênero . Tese (Doutorado). Programa de Pós-Graduação em Sociologia, Universidade do Estado do Rio de Janeiro, Rio de Janeiro, 2015, p. 152. Disponível em: http://ceres.iesp.uerj.br/wpcontent/uploads/2016/05/Mudan\%C3\%A7as-nas-fam\%C3\%ADlias-no-Brasil-1976-2012-uma-

perspectiva-de-classe-e-g\%C3\%AAnero-Nathalie-Reis-Itabora\%C3\%AD.pdf. Acesso em 10, nov. 2019.

${ }^{33}$ Anuário Brasileiro de Segurança Pública. FÓRUM BRASILEIRO DE SEGURANÇA PÚBLICA. ISSN 1983-7364, ano 13. Edição 2019, p. 108-116. Disponível em: http://www.forumseguranca.org.br/wpcontent/uploads/2019/10/Anuario-2019-FINAL_21.10.19.pdf. Acesso em 08, nov. 2019.

34 Atlas da violência 2019. / Organizadores: Instituto de Pesquisa Econômica Aplicada; Fórum Brasileiro de Segurança Pública. Brasília: Rio de Janeiro: São Paulo: Instituto de Pesquisa Econômica Aplicada; Fórum Brasileiro de Segurança Pública, p. 35-39. Disponível em http://www.ipea.gov.br/portal/images/stories/PDFs/relatorio_institucional/190605_atlas_da_violencia_ 2019.pdf. Acesso em 08, nov 2019. 
entre homens e mulheres e para a efetiva implementação dos direitos das mulheres, no sentido de garantir que o Estado der a atenção devida aos temas que afetam a saúde das mulheres, e os direitos sexuais e reprodutivos ${ }^{35}$.

A luta pela autonomia reprodutiva das mulheres está ligada, a luta pela apropriação do próprio corpo, a crítica à 'medicalização' do mesmo e, por fim, a luta pelos direitos reprodutivos básicos, expressos no princípio da livre escolha, seja a da contracepção, ou de aborto livres e gratuitos. Como resultado dessas lutas, conquistadas começam a surgir como o Programa de Atenção à Saúde Integral das Mulheres (PAISM), as políticas de atenção à feminização da epidemia de Aids, elementos da estratégia Rede Cegonha, a participação de mulheres nos debates sobre políticas públicas de saúde, a Norma Técnica de Atenção Humanizada ao Abortamento do Ministério da Saúde, que estabelece normas gerais de acolhimento, orientação e atenção clínica as mulheres que passaram e passam por abortos espontâneos ou provocados - e procuram assistência em unidades de saúde públicas ou privadas ${ }^{36}$, todas essas questões tem um olhar cuidadoso e especial pela Bioética Feminista, e a luta do feminismo.

No entanto, lutar para ter direito a saúde, só deixa transparecer a desigualdade que assola as mulheres, mulheres que há décadas, buscam direitos, entre eles o acesso aos serviços e ações de saúde de qualidade, e a implantação de políticas públicas que incluem a saúde sexual e reprodutiva. Posto que, uma das desigualdades mais marcantes é o que está disposto no $\S 5^{\circ}$ do art. 10 da Lei $n$.

35 Galli Bevilacqua, Maria Beatriz, Direitos Sexuais e Reprodutivos, Autonomia Reprodutiva, Política E (Des) Respeito ao Princípio da Laicidade (Direitos Sexuais e Reprodutivos, Autonomia Reprodutiva, Política e (Des) Respeito ao Princípio do Secularismo) (20 de julho de 2014) p. 01. Disponível

SSRN: https://ssrn.com/abstract=2484236 ou http://dx.doi.org/10.2139/ssrn.2484236. Acesso em 11 de nov. 2019.

${ }^{36}$ Galli Bevilacqua, Maria Beatriz, Direitos Sexuais e Reprodutivos, Autonomia Reprodutiva, Política E (Des) Respeito ao Princípio da Laicidade (Direitos Sexuais e Reprodutivos, Autonomia Reprodutiva, Política e (Des) Respeito ao Princípio do Secularismo) (20 de julho de 2014) p. 01. Disponível

SSRN: https://ssrn.com/abstract=2484236 ou http://dx.doi.org/10.2139/ssrn.2484236. Acesso em 11 de nov. 2019. 
9.263/96, que determina que, na vigência da sociedade conjugal, a esterilização depende do consentimento expresso de ambos os cônjuges ${ }^{37}$.

Embora de início, pareça o dispositivo compatível com a igualdade de gênero, eis que exige o consentimento de ambos os cônjuges para a esterilização voluntária durante a vigência da sociedade conjugal, além do preenchimento dos demais requisitos previstos no art. 10 da Lei do Planejamento Familiar, portanto a questão da mulher, ainda é marcada por uma vulnerabilidade e desigualdade de gênero, pois impor à mulher casada a exigência de consentimento para realizar a esterilização é mais uma limitação à sua autonomia ${ }^{38}$.

\section{DESIGUALDADE DE GENÊRO NO BRASIL}

São recentes no Direito brasileiro, as menções ao gênero de uma pessoa, visto que tradicionalmente considerava-se apenas o sexo biológico de alguém. Os debates no campo jurídico se deram por intermédio de jurisprudências, em razão das demandas judiciais para o reconhecimento da "identidade de gênero", propostas pelos integrantes da população LGBTQIA+, sobretudo pelas transexuais que queriam "mudar de sexo" 39.

Engels ${ }^{40}$ descreve que, a história primitiva revela-nos um estado de coisas, que os homens praticam a poligamia e suas mulheres a poliandria, e em que, por consequência, os filhos de uns e os outros tinham que ser considerados comuns. Com o tempo, esse estado de coisas, passando por uma série de transformações, resulta na monogamia, que é o casal isolado de hoje.

\footnotetext{
${ }^{37}$ BARBOZA, Heloisa Helena Gomes; JUNIOR, Vitor de Azevedo Almeida. (Des)Igualdade de gênero: restrições à autonomia da mulher. Revista de ciências Jurídicas. Pensar, Fortaleza, v. 22, n. 1, jan./abr. 2017, p. 240-271.

${ }^{38}$ BARBOZA, Heloisa Helena Gomes; JUNIOR, Vitor de Azevedo Almeida. (Des)lgualdade de gênero: restrições à autonomia da mulher. Revista de ciências Jurídicas. Pensar, Fortaleza, v. 22, n. 1, jan./abr. 2017, p. 240-271.

${ }^{39}$ BARBOZA, Heloisa Helena Gomes; JUNIOR, Vitor de Azevedo Almeida. (Des)Igualdade de gênero: restrições à autonomia da mulher. Revista de ciências Jurídicas. Pensar, Fortaleza, v. 22, n. 1, jan./abr. 2017, p. 240-271.

40 ENGELS, Friedrich. A Origem da Família, da Propriedade Privada e do Estado. Civilização brasileira. 9 edição. Rio de Janeiro, Rj, 1984, p. 31.
} 
Há poucas décadas, o sexo tinha o propósito de procriação, de modo que havia forte repressão às relações sexuais realizadas fora do casamento, (sobretudo em relação à mulher que deveria casar-se virgem) ou dos padrões socialmente aceitos e estabelecidos, a fidelidade sexual feminina contava como a única garantia da paternidade, e em consequência, da legitimidade da prole, muito embora, o comportamento masculino não era só tolerado, mas aceito e até mesmo incentivado pelos pais (figura paterna), não ocorrendo o mesmo com as mulheres. Uma visão sociobiológica da discriminação sexual, que percebe o homem como o ser ativo, portanto predisposto ao combate público e ao sucesso, e a mulher a detentora biológica da passividade e orientada para a procriação e o cuidado da casa, nada mais do que uma posição ideológica patriarcal e social-darwinista ${ }^{41}$.

Contemporaneamente, as mulheres continuam sendo o maior alvo da repressão sexual, o que revela o tipo de educação e socialização que era/ e é dada pelas gerações aos seus membros, definindo uma desigualdade de gênero, que ultrapassa gerações, de certa forma naturalizada. Engels ${ }^{42}$ aponta que essa desigualdade legal, que herdamos de condições sociais anteriores, não é causa e sim efeito da opressão econômica da mulher.

A mulher não poderia permitir intimidade com um homem que não fosse seu marido, mas mesmo com este, não deveria demonstrar interesse sexual e muito menos desejo e prazer, esse era um dos aconselhamentos dados no dia do matrimônio, para as noites de núpcias e para a vida, pois "mulher de boa família" não poderia demostrar vontades e/ ou desejos sexuais. Conforme Engels ${ }^{43}$ existia, uma escravidão junto á monogamia, a presença de jovens e belas cativas que pertencem de corpo e alma, ao homem, é o que imprime desde a origem um caráter específico que a monogamia era só para a mulher, e não para o homem. E, na atualidade, conserva-se esse caráter.

${ }^{41}$ SILVA, Manuel Carlos « Desigualidades de género », Configurações [Online], 4 | 2008, posto online no dia 12 fevereiro 2012, consultado o 19 abril 2019, p. 02. Disponível em URL : http://journals.openedition.org/ configuracoes/370 ; DOI : 10.4000/configuracoes.370. Acesso em $01 \mathrm{de}$ dez 2019.

42 ENGELS, Friedrich. A Origem da Família, da Propriedade Privada e do Estado. Civilização brasileira. 9 edição. Rio de Janeiro, Rj, 1984, p. 79.

43 ENGELS, Friedrich. A Origem da Família, da Propriedade Privada e do Estado. Civilização brasileira. 9 edição. Rio de Janeiro, Rj, 1984, p. 67. 
Esse cenário muda com a entrada da mulher no mercado de trabalho, e aqui se ressalta que as mulheres negras já pertenciam a esse mercado de trabalho, e agora também veem ocupar os espaços nos lares, nos trabalhos domésticos, para que essas mulheres ingressem no mercado também. Então é com a inserção dessa outra parcela de mulheres no mercado, juntamente com as lutas de movimentos sociais e o avanço científico que contribuíram para uma pequena mudança social, porém significativa.

A criação da pílula anticoncepcional nos anos 1960 deu maior autonomia à mulher quanto à sua sexualidade. Hoje, com a existência de diversos métodos contraceptivos e da camisinha masculina e feminina, o sexo pode ser realizado com maior segurança e liberdade ${ }^{44}$.

Desigualdades de gênero nas famílias ainda conferem as responsabilidades de cuidado majoritariamente às mulheres, levando a questionar se o status de indivíduo é compatível com o de mãe. Isso, por conta da incompatibilidade que tais papéis sociais representariam na vida dessa mulher, pois o lugar de mulher, mãe e esposa, presa ao lar, impediria essa individualização, essa singularidade enquanto ser autônomo, político e social. É através da revolta, da recusa dessa limitação imposta, que algumas mulheres forjam sua libertação, o que não impede que a maternidade persista no horizonte dos projetos de grande parte das mulheres, todavia, elas hoje têm menos filhos e para uma parte delas a maternidade é um evento mais tardio. ${ }^{45}$.

Uma grande barreira, atualmente ainda é a falta do diálogo, de educação sexual na família e nas escolas. A sociedade precisa conversar abertamente sobre

\footnotetext{
44 ITABORAÍ, Nathalie Reis.Mudanças nas famílias brasileiras (1976-2012): uma perspectiva de classe e gênero . Tese (Doutorado). Programa de Pós-Graduação em Sociologia, Universidade do Estado do Rio de Janeiro, Rio de Janeiro, 2015, p. 213. Disponível em: http://ceres.iesp.uerj.br/wpcontent/uploads/2016/05/Mudan\%C3\%A7as-nas-fam\%C3\%ADlias-no-Brasil-1976-2012-umaperspectiva-de-classe-e-g\%C3\%AAnero-Nathalie-Reis-Itabora\%C3\%AD.pdf. Acesso em 10, nov. 2019.

45 ITABORAÍ, Nathalie Reis.Mudanças nas famílias brasileiras (1976-2012): uma perspectiva de classe e gênero . Tese (Doutorado). Programa de Pós-Graduação em Sociologia, Universidade do Estado do Rio de Janeiro, Rio de Janeiro, 2015, p. 152. Disponível em: http://ceres.iesp.uerj.br/wpcontent/uploads/2016/05/Mudan\%C3\%A7as-nas-fam\%C3\%ADlias-no-Brasil-1976-2012-uma-

perspectiva-de-classe-e-g\%C3\%AAnero-Nathalie-Reis-Itabora\%C3\%AD.pdf. Acesso em 10, nov. 2019.
} 
sexualidade, gravidez indesejada, doenças sexualmente transmissíveis, a falta de conhecimento pelos pais, pode ser uma das barreiras nesse diálogo, mas há outros entraves presentes como o próprio bloqueio do adolescente, visto que eles reagem alegando que já possuem conhecimento prévio sobre o assunto e que não são mais crianças. A dificuldade de diálogo com os pais se deve também a diferenças geracionais, segundo os jovens, que consideram seus pais mais rígidos, apelando para punições e castigos, quebrar essas barreiras e falar sobre sexo, sobre prazer, tanto com as meninas, quanto com os meninos é fundamental, e tudo isso faz parte da educação sexual que pode ser transmitida pela escola, e pelos profissionais de saúde $^{46}$. O conhecer dá autonomia à mulher e amplia as possibilidades de expressão e exercício da própria sexualidade.

No entanto, estudiosos no campo da sexualidade alertam sobre o perigo de que a focalização em temas relacionados à sexualidade na escola, nos meios de comunicação e por outras agências, assim como por adultos em suas interações com crianças, adolescentes e jovens se distanciem de tal forma, que não necessariamente contribuiriam para pedagogias sobre o prazer e um diálogo agradável. Adverte-se ainda que tais saberes possam contribuir para a reprodução de estereótipos, por isso há necessidade de ser alguém especializado ${ }^{47}$.

Outra barreira que a mulher enfrenta, é a vinculação da imagem feminina (partes de seu corpo e em sua maioria partes determinadas - Colo e Nádegas), apresentada em programas de televisão, propagandas, sites, na mídia em geral, a forma feminina é frequentemente usada de maneira sexualidade, com apelo sensual para comercialização (venda de um produto), reduzindo a mulher a um corpo, a uma parte especifica desse corpo, no qual se percebe a discriminação, as desigualdades, e a desvalorização que é dada a mulher socialmente, umas ações mais diretas, outras

\footnotetext{
${ }^{46}$ ABRAMOVAY, Miriam. Juventude e sexualidade / Miriam Abramovay, Mary Garcia Castro e Lorena Bernadete da Silva. Brasília: UNESCO Brasil, 2004, p.103-126. Disponível em: http://www.cepac.org.br/agentesdacidadania/wpcontent/uploads/2014/04/Unesco_juventudes_sexualidade.pdf. Acesso em 03 de dez de 2019.

${ }^{47}$ ABRAMOVAY, Miriam. Juventude e sexualidade / Miriam Abramovay, Mary Garcia Castro e Lorena Bernadete da Silva. Brasília: UNESCO Brasil, 2004, p.103-126. Disponível em: http://www.cepac.org.br/agentesdacidadania/wpcontent/uploads/2014/04/Unesco_juventudes_sexualidade.pdf. Acesso em 03 de dez de 2019.
} 
mais sutis/ veladas. Como Rita Segato ${ }^{48}$ alerta o corpo feminino e feminizado é o território mais violado e violentado.

Segundo o Relatório de Desenvolvimento Humano do Programa das Nações Unidas para o Desenvolvimento, o Brasil ocupa a 85a posição em desenvolvimento humano e desigualdade de gênero, embora seja um dos países em destaque no relatório da ONU Mulheres, devido ao seu papel na geração de trabalho decente para as mulheres, $25 \%$ das brasileiras têm trabalho precário, que apresenta algum risco ou trabalha sem proteção social, com isso é o país que mais perde posições no ranking mundial do Índice de Desenvolvimento Humano (IDH). Quando esse valor é ajustado à desigualdade, ou seja, quando se leva em consideração as distorções em saúde, educação e renda, o Brasil caiu 23 posições $(0,761$ para 0,574$)$, uma perda de $24,57 \%$ no valor, quando comparado ao restante do mundo. E fica mais alarmante, quando se considera que um terço das famílias brasileiras são chefiadas por mulheres, e metade delas são monoparentais ${ }^{49}$.

É diante dessa realidade sociocultural marcada pela desigualdade, que se deve promover uma igualdade substancial, que vise tutelar a dignidade social e a autonomia da mulher de forma efetiva, pois as desigualdades no acesso das mulheres à saúde reprodutiva é parte do campo mais amplo das desigualdades no acesso à saúde ${ }^{50}$.

48 SEGATO, Rita Laura. As novas formas de guerra e o corpo das mulheres. Soc. State. , Brasília, v. 29 , n. 2, p. 341-371, agosto de 2014. Disponível em <http://www.scielo.br/scielo.php? script=sci_arttext\&pid=S0102-69922014000200003\&lng=en\&nrm=iso>. Acesso em 06 nov. 2019.

${ }^{49}$ BARBOZA, Heloisa Helena Gomes; JUNIOR, Vitor de Azevedo Almeida. (Des)lgualdade de gênero: restrições à autonomia da mulher. Revista de ciências Jurídicas. Pensar, Fortaleza, v. 22, n. 1, jan./abr. 2017, p. 240-271.

50 ITABORAÍ, Nathalie Reis.Mudanças nas famílias brasileiras (1976-2012): uma perspectiva de classe e gênero . Tese (Doutorado). Programa de Pós-Graduação em Sociologia, Universidade do Estado do Rio de Janeiro, Rio de Janeiro, 2015, p. 247. Disponível em: http://ceres.iesp.uerj.br/wpcontent/uploads/2016/05/Mudan\%C3\%A7as-nas-fam\%C3\%ADlias-no-Brasil-1976-2012-uma-

perspectiva-de-classe-e-g\%C3\%AAnero-Nathalie-Reis-Itabora\%C3\%AD.pdf. Acesso em 10, nov. 2019. 


\section{CONSIDERAÇÕES FINAIS}

Hoje, há uma presença expressiva de mulheres atuantes na perspectiva e aplicação da bioética no Brasil, e isso é bastante relevante para os estudos que estão sendo desenvolvidos e pensados na área.

Em relação, a linha da Bioética Feminista, vê-se que é uma linha que traz consigo os conceitos de gênero, raça, etnia, vulnerabilidades e direitos humanos, e por apresentar uma vertente auto-reflexiva e dialógica da bioética. A bioética quando pensa as questões de gênero e feminismo busca compreender e apreender a diferença moral entre as partes em conflito. Portanto, tem-se um ganho enorme por parte da sociedade, da academia e dos estudiosos, que lutam e acreditam nos pressupostos da dignidade humana, liberdade, igualdade de direitos e democracia.

Constatou-se, que os direitos femininos foram conquistados em resposta à mobilização social, em especial do movimento feminista e do movimento de mulheres, que se mobilizaram por direitos reprodutivos. Esse protagonismo, nas mudanças no processo de formação de família, beneficiou as mudanças no mercado, já que a expansão das oportunidades de trabalho permitiu novos espaços de identidade feminina que competem com a formação de família e autonomia das mulheres.

Essas mulheres protagonizaram suas revoluções pessoais, transformando suas famílias, optando por ter menos filhos ou não os ter. No entanto, é visível que o esforço das mulheres tem limite, diante das desigualdades de gênero que persistem no âmbito privado e público, e deve-se notar que as desigualdades sociais tanto de classe e gênero estão presentes no cotidiano feminino. Verificou-se que a busca das mulheres por direitos, entre eles, o acesso às ações e serviços de saúde, perdura-se por décadas, e que vários grupos feministas, a partir de suas lutas e ideologias, conseguiram amenizar a forma como a mulher é vista na sociedade, principalmente, quando se trata dos direitos sexuais e reprodutivos.

Enfim, diante desse cenário percebe-se que há interferência na autonomia reprodutiva feminina presente, efetiva e atuante, por isso, há de se pensar em novos direitos, ante as desigualdades de gênero, além dos direitos reprodutivos e suas políticas públicas. 


\section{REFERÊNCIA}

ABRAMOVAY, Miriam. Juventude e sexualidade / Miriam Abramovay, Mary Garcia Castro e Lorena Bernadete da Silva. Brasília: UNESCO Brasil, 2004, p.103-126. Disponível em: http://www.cepac.org.br/agentesdacidadania/wpcontent/uploads/2014/04/Unesco_juventudes_sexualidade.pdf . Acesso em 03 de dez de 2019.

AGUIAR, Mônica Neves. MEIRELLES, Ana Thereza. Autonomia e Alteridade como fundamentos da construção do sentido de dignidade existencial diante do direito à vida. Revista Brasileira de Direito Animal. RBDA, SALVADOR, V.13, N. 01, PP. 123-147, Jan-Abr 2018.

ANIS - Instituto de Bioética. Aborto: por que precisamos descriminalizar? : argumentos apresentados ao Supremo Tribunal Federal na Audiência Pública da ADPF 442 /- Brasília: 48p. Letras Livres, 2019.

ANJOS, K. F.; SANTOS, V. C.; SOUZAS, R.; EUGÊNIO, B. G. • Aborto e saúde pública no Brasil: reflexões sob a perspectiva dos direitos humanos. Saúde em Debate - Rio de Janeiro, v. 37, n. 98, p. 504-515, jul/set 2013. Disponível em https://www.scielosp.org/pdf/sdeb/2013.v37n98/504-515/pt. Acesso em 10 out. 2019.

Anuário Brasileiro de Segurança Pública. FÓRUM BRASILEIRO DE SEGURANÇA PÚBLICA. ISSN 1983-7364, ano 13. Edição 2019, p. 108-116. Disponível em: http://www.forumseguranca.org.br/wp-content/uploads/2019/10/Anuario-2019FINAL_21.10.19.pdf. Acesso em 08, nov. 2019.

Atlas da violência 2019. / Organizadores: Instituto de Pesquisa Econômica Aplicada; Fórum Brasileiro de Segurança Pública. Brasília: Rio de Janeiro: São Paulo: Instituto de Pesquisa Econômica Aplicada; Fórum Brasileiro de Segurança Pública, p. 35-39.

Disponível

em http://www.ipea.gov.br/portal/images/stories/PDFs/relatorio_institucional/190605_atla s_da_violencia_2019.pdf. Acesso em 08, nov 2019.

BADINTER, Elisabeth. B126a. Um Amor conquistado: o mito do amor materno. Elisabeth Badinter; tradução de Waltensir Dutra. - Rio de Janeiro: Nova Fronteira, 1985.

BANDEIRA, Lourdes. ALMEIDA, Tânia Mara Campos de. Bioética e feminismo: um diálogo em construção. Revista de Bioética. 2008. 
BARBOZA, Heloisa Helena Gomes; JUNIOR, Vitor de Azevedo Almeida. (Des)Igualdade de gênero: restrições à autonomia da mulher. Revista de ciências Jurídicas. Pensar, Fortaleza, v. 22, n. 1, jan./abr. 2017 p. 240-271.

BARROSO, Luís Roberto. Interpretação e Aplicação da Constituição: Fundamentos da Dogmática Constitucional Transformadora. 6aㅡ ed. ver. atual. e ampl. São Paulo: Saraiva, 2004, p. 222-223.

BEAUCHAMP,TL, CHILDRESS JF. Principles of biomedical ethics. 3rd ed. New York (NY): Oxford University Press; 1989.

BEAUVOIR, Simone de. O segundo sexo: fatos e mitos. Trad. Sérgio Milliet. 3 ed. Rio de Janeiro: Nova Fronteira, 2016.

BRASIL. LEI № 9.263, Lei Planejamento Familiar. Brasília. 12 DE JANEIRO DE 1996.

BRASIL. Ministério da Saúde. Secretaria de Atenção à Saúde. Departamento de Ações Programáticas Estratégicas. Atenção humanizada ao abortamento: norma técnica. Ministério da Saúde, Secretaria de Atenção à Saúde, Área Técnica de Saúde da Mulher. - 2. ed. - Brasília : Ministério da Saúde, 2011.

BRASIL. Ministério da Saúde. Secretaria de Atenção à Saúde. Departamento de Ações Programáticas Estratégicas. Área Técnica de Saúde da Mulher. Atenção Humanizada ao Abortamento: norma técnica/Ministério da Saúde, Secretaria de Atenção à Saúde, Departamento de Ações Programáticas Estratégicas - Brasília: Ministério da Saúde, p. 22. 2005.

CHODOROW, Nancy. Psicanálise da Maternidade: Uma Crítica a Freud a Partir da Mulher. Rio de Janeiro: Rosa dos Tempos, 1991.

CONPEDI/ UNISINOS. Biodireito e direitos dos animais [Recurso eletrônico on-line]. ECOFEMINISMO E DIREITO ANIMAL. Organização Coordenadores: Valéria Silva Galdino Cardin; Heron José de Santana Gordilho. - Florianópolis: CONPEDI, p.126. 2018. ISBN: 978-85-5505-685-7. Disponível em: http://conpedi.danilolr.info/publicacoes/34q12098/ryzk920n/T6peyBzVU76ft2Tx.pdf. Acesso em 14 nov. 2019.

CONSELHO FEDERAL DE MEDICINA. Iniciação à bioética. Sergio Ibiapina Ferreira Costa, Gabriel Oselka, Volnei Garrafa, coordenadores. - Brasília : 1998. 
CRUZ, Maria Helena Santana. Mapeando diferenças de gênero no ensino superior da Universidade Federal de Sergipe. São Cristóvão: Editora UFS, 2012.

Diniz, Debora. ALMEIDA. Marcos de. Bioética e Aborto. In. Iniciação a Bioética. Brasília: Conselho Federal de Medicina. 1998.

DINIZ, Debora. Autonomia reprodutiva: um estudo de caso sobre a surdez. Rio de Janeiro: Cad. Saúde Pública. 2003.

DINIZ, Débora. Bioética e gênero. Revista Bioética. Capa> v. 16, n.2> Diniz. 2008, p. $208 . \quad$ Disponível em http://revistabioetica.cfm.org.br/index.php/revista_bioetica/article/view/68/71. Acesso em 30 nov. 2019.

ENGELS, Friedrich. A Origem da Família, da Propriedade Privada e do Estado. Civilização brasileira. 9 edição. Rio de Janeiro, Rj, 1984.

FAUTH, Juliana de Andrade. Entendendo o direito animal e o especismo: uma breve leitura ecofeminista. Revista Jus Navigandi, ISSN 1518-4862, Teresina, ano 19, n. 3915, 21 mar. 2014. Disponível em: https://jus.com.br/artigos/27043. Acesso em: 19 nov. 2019.

FERRER, Jorge José; ALVAREZ, Juan Carlos. Para fundamentar a bioética. Teorias e paradigmas teóricos na bioética contemporânea. São Paulo: Loyola. 2005.

FRIEDE, Reis. Aborto: uma questão jurídica e de saúde pública. Revista da Escola da Magistratura do TRF da 4a Região n. 11, ano 5. p. 62. 2019. Disponível em: http://www.mpsp.mp.br/portal/page/portal/documentacao_e_divulgacao/doc_bibliotec a/bibli_servicos_produtos/bibli_boletim/bibli_bol_2006/RevEMAGIS11.pdf. Acesso em 13 nov. $201 \overline{9}$.

GALLI, Beatriz. ROCHA, Helena. Direitos Sexuais e Reprodutivos, Autonomia Reprodutiva, Política e (des) respeito ao Princípio da Laicidade. Relatoria do Direito Humano à Saúde Sexual e Reprodutiva. Plataforma de Direitos Humanos. DHESCA Brasil. Julho/2014.

ITABORAÍ, Nathalie Reis.Mudanças nas famílias brasileiras (1976-2012): uma perspectiva de classe e gênero . Tese (Doutorado). Programa de Pós-Graduação em Sociologia, Universidade do Estado do Rio de Janeiro, Rio de Janeiro, 2015, p. 152. Disponível em: http://ceres.iesp.uerj.br/wpcontent/uploads/2016/05/Mudan\%C3\%A7as-nas-fam\%C3\%ADlias-no-Brasil-1976- 
2012-uma-perspectiva-de-classe-e-g\%C3\%AAnero-Nathalie-ReisItabora\%C3\%AD.pdf. Acesso em 10, nov. 2019.

LUIZ, Carmen Lucia. Mulheres em situação de abortamento: um olhar sobre o acolhimento. In: Em defesa da vida: aborto e direitos humanos / Alcilene Cavalcante, Dulce Xavier (organizadoras). São Paulo: Católicas pelo Direito de Decidir, p. 101. 2006.

MARCOLINO, Jan; COHEN, C. Sobre a correlação entre a bioética e a psicologia médica. Rev. Assoc. Med. Bras. 2008.

MINISTÉRIO DA SAÚDE. Secretaria de Atenção à Saúde, Departamento de Ações Programáticas Estratégicas. Brasília. Direitos sexuais e reprodutivos. Ministério da Saúde, $4^{0}$ Edição - Abril de 2017.

MINISTÉRIO DA SAÚDE. Secretaria de Atenção à Saúde, Departamento de Ações Programáticas Estratégicas. Direitos sexuais, direitos reprodutivos e métodos anticoncepcionais. Brasília: Ministério da Saúde, 2006.

NÚCLEO ESPECIALIZADO DE PROMOÇÃO E DEFESA DOS DIREITOS DA MULHER. Liberdade Sexual. Coordenadoria de Comunicação Social e Assessoria de Imprensa da Defensoria Pública do Estado São Paulo. São Paulo. 2013.

PIOVESAN, Flávia. Direitos humanos e o direito constitucional internacional. 14 edição, rev. e atual. São Paulo: Saraiva, 2013.

SCAVONE. Lucila. Das diferenças às desigualdades: reflexão sobre o conceito de saúde reprodutiva nas ciências sociais. GOLDENBERG, P., MARSIGLIA, RMG and GOMES, MHA., orgs. In. O Clássico e o Novo: tendências, objetos e abordagens em ciências sociais e saúde [online]. Rio de Janeiro: Editora FIOCRUZ, 2003. 444 p. ISBN 85-7541-025-3. Available from SciELO Books.

SCOOTT, Joan W. 0 enigma da igualdade. Rev. Estud. Fem. v.13 n.1 Florianópolis jan./abr. 2005.

SEGATO, Rita Laura. As novas formas de guerra e o corpo das mulheres. Soc. State., Brasília, v. 29, n. 2, p. 341-371, agosto de 2014. Disponível em <http://www.scielo.br/scielo.php? script=sci_arttext\&pid=S010269922014000200003\&lng=en\&nrm=iso >. Acesso em 06 nov. 2019. 
SILVA, Manuel Carlos «Desigualidades de género », Configurações [Online], 4 | 2008, posto online no dia 12 fevereiro 2012, consultado o 19 abril 2019, p. 02. Disponível em URL: http://journals.openedition.org/ configuracoes/370 ; DOI : 10.4000/configuracoes.370. Acesso em 01 de dez 2019.

TAVARES, Rebecca. Discurso. In: BRASIL, Ministério das Relações Exteriores. Autonomia econômica e empoderamento da mulher - textos acadêmicos. Brasília: Fundação Alexandre de Gusmão, 2011.

TEIXEIRA, Simone Andrade. FERREIRA. Silva Lúcia. Direitos Sexuais e direitos reprodutivos: teorias e práxis de feministas acadêmicas. In. Gênero, mulheres e feminismos / Alinne Bonneti e Ângela Maria Freire de Lima e Souza (org.). (Coleção Bahianas ; 14)- 346 p. - Salvador : EDUFBA : NEIM, 2011.

VARES, Sidnei Ferreira de. SOCIOLOGISMO E INDIVIDUALISMO EM ÉMILE DURKHEIM. CADERNO CRH, RESENHA TEMÁTICA. Salvador, v. 24, n. 62, Maio./Ago. 2011. p. 435-446. Disponível em http://dx.doi.org/10.1590/S010349792011000200013. Acesso em 26 de nov. 2019. 